\title{
Episodic atmospheric changes and their impact on the hydrography of coastal waters in Tanzania
}

\author{
Ntahondi Nyandwi*, Alfonse M. Dubi \\ Institute of Marine Sciences, University of Dar es Salaam, PO Box 668, Zanzibar, Tanzania
}

\begin{abstract}
A shift in the time of occurrence and duration of the rainy and dry seasons has been observed over Tanzania and the East African region in recent years. During 1998, El Niño rains produced substantial fresh water and sediment supply to the coastal zone. During that period, large sand bodies were deposited off river mouths and at stream entrances. Hydrographic measurements showed a persistent decrease in salinity and temperature of inshore waters indicating that coastal waters have been trapped along the shore. Such environmental changes could have negative effects on the biodiversity of the coastal zone. Based on beach profile measurements, the shoreline was predominantly eroding prior to the rains but accreted during the El-Niño rains. The tidal flats received a larger volume of sand. While the beach and tidal flats were receiving this supply of sand, river banks eroded as channels deepened and widened. In many instances, newly cut flood channels have remained semi-permanent serving as tidal inlets leading to tidal inundation of the low lying areas behind the beaches. These observations point to the significance of episodic events in maintaining or shaping the coastal zone.
\end{abstract}

KEY WORDS: Hydrography $\cdot$ El-Niño rains $\cdot$ Beach profiles $\cdot$ Erosion $\cdot$ Accretion

\section{INTRODUCTION}

In Tanzania, coastal waters serve as the main source of seafood, both fin-fish and crustaceans. The productivity of coastal waters generally depends on the linkage between the hinterland and the marine environments, such that the foodweb is not disrupted. The biological productivity of any part of the world ocean also depends on the hydrography of the water mass concerned. Changes in hydrographic conditions in an area may be due to changes in global circulation as a result of climatic changes or may be a local feature caused by factors such as atmospheric conditions.

The coastal zone is a region in which human settlement has traditionally been on the increase. Most of the large cities of the world are found within the coastal zone. In developing countries, tourism and industrial development have concentrated on the

*E-mail: nyandwi@zims.udsm.ac.tz coast. As such, the coastal zone is an economically and socially important resource that must be well managed and whose destruction may deny humankind its livelihood.

Whereas coastal protection designs in storm-prone or subsiding coastal areas in the developed world have taken into account episodic factors including their frequency and intensity, the practice in the East African region, and in Tanzania in particular, has been characterized by a lack of baseline data and guidelines. Tourist hotels are built on beaches very close to the sea and governments have no legislation on setback lines or protection structures. The coastal zone is a very delicate environment and any changes in the zone must be assessed for their impacts. The El-Niño episode in the Indian Ocean and its effects as observed in the coastal waters of Tanzania during 1998 demonstrate the impact of episodic events on hydrography and the coastal zone. The hydrographic changes may impact the biodiversity of coastal waters. 


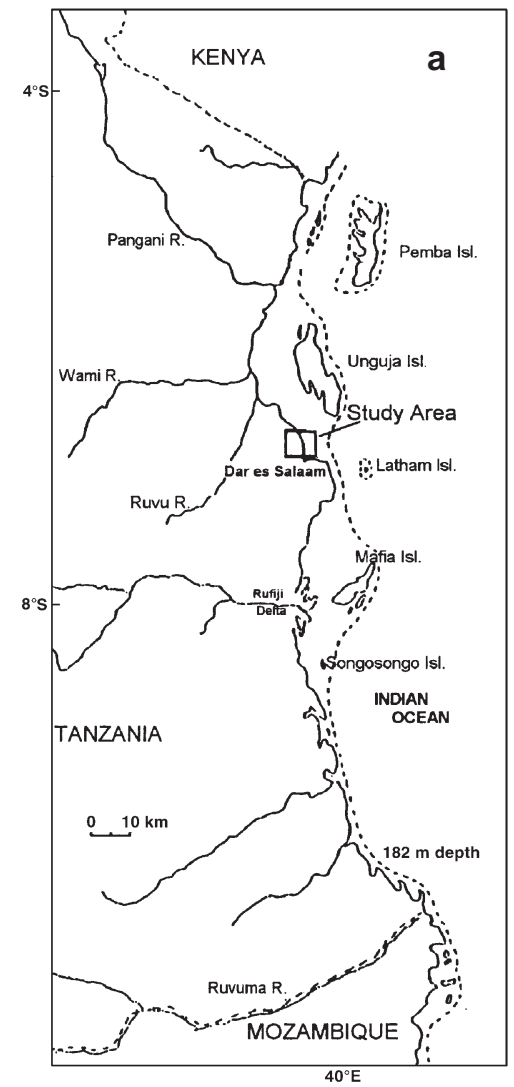

\section{STUDY AREA}

Tanzania lies south of the equator, between latitudes $4^{\circ} \mathrm{S}$ to $11^{\circ} 45^{\prime} \mathrm{S}$ and $29^{\circ} 21^{\prime} \mathrm{E}$ to $40^{\circ} 25^{\prime} \mathrm{E}$, covering an area of $945200 \mathrm{~km}^{2}$. This area includes the Zanzibar Islands, i.e. Unguja and Pemba, which cover an area of $1500 \mathrm{~km}^{2}$ and $900 \mathrm{~km}^{2}$ respectively. The coastline of Tanzania is $800 \mathrm{~km}$ long and the land area of the coastal zone is $\sim 30000 \mathrm{~km}^{2}$ (Fig.1). The width of the continental shelf ranges between $4 \mathrm{~km}$ and $35 \mathrm{~km}$. The islands within the continental shelf include Unguja, Pemba, and Mafia, as well as numerous small but beautiful islands and reefs such as Latham, Tutia, Songosongo and Mbudya.

Tanzania, like all countries bordering the Indian Ocean, is affected by the monsoons, which control atmosphere-ocean dynamics in the region. The monsoons influence wind direction and speed, temperature, rainfall etc. The NE monsoon season (October to March) is characterized by weaker winds, while during the SE monsoon (April to September) the winds are stronger (Newell 1957). The months of March/April and October/November are the inter-monsoonal periods and usually are the calmest. The period March to June experiences long and heavy rains, whereas short and light rains occur during October/November. The period June/July is the coolest (average temperature $\left.24^{\circ} \mathrm{C}\right)$, while February/March is the warmest $\left(\sim 30^{\circ} \mathrm{C}\right)$. Sea surface temperature of coastal waters varies in a similar pattern, with an average of $28^{\circ} \mathrm{C}$ during February/March and between 25 and $26^{\circ} \mathrm{C}$ during June/July (Newell 1957). Typical salinity values of coastal waters range between 34 and $35.2 \%$.

Numerous minor and major rivers drain into coastal Tanzania. From the southern border northwards, the big rivers are Ruvuma, Mbwemukulu, Rufiji, Ruvu and Pangani (Fig. 1a). The area north of the city of Dar es Salaam where the field measurements were carried out (Fig. 1b), is drained by small streams with steep valleys that dissect higher grounds of Tertiary claybound sands and gravels. The natural vegetation has been largely cleared as a result of human settlement and agriculture.

\section{FIELD EXPERIMENT}

During 1997/98, a field study was initiated on the Tanzania coast to monitor hydrographic changes with the monsoons and associated beach response. A selfrecording current meter (RCM9, Aanderaa Instuments, Bergen) was installed in the intertidal zone at Kunduchi. The instrument records current speed and direction, temperature, salinity, instrument depth, and turbidity. It was deployed in the field for 1 mo on each field trip. One of the aims was to compare the conditions between rainy (NE monsoon) and dry (SE monsoon) seasons. Beach profiles and sediment 


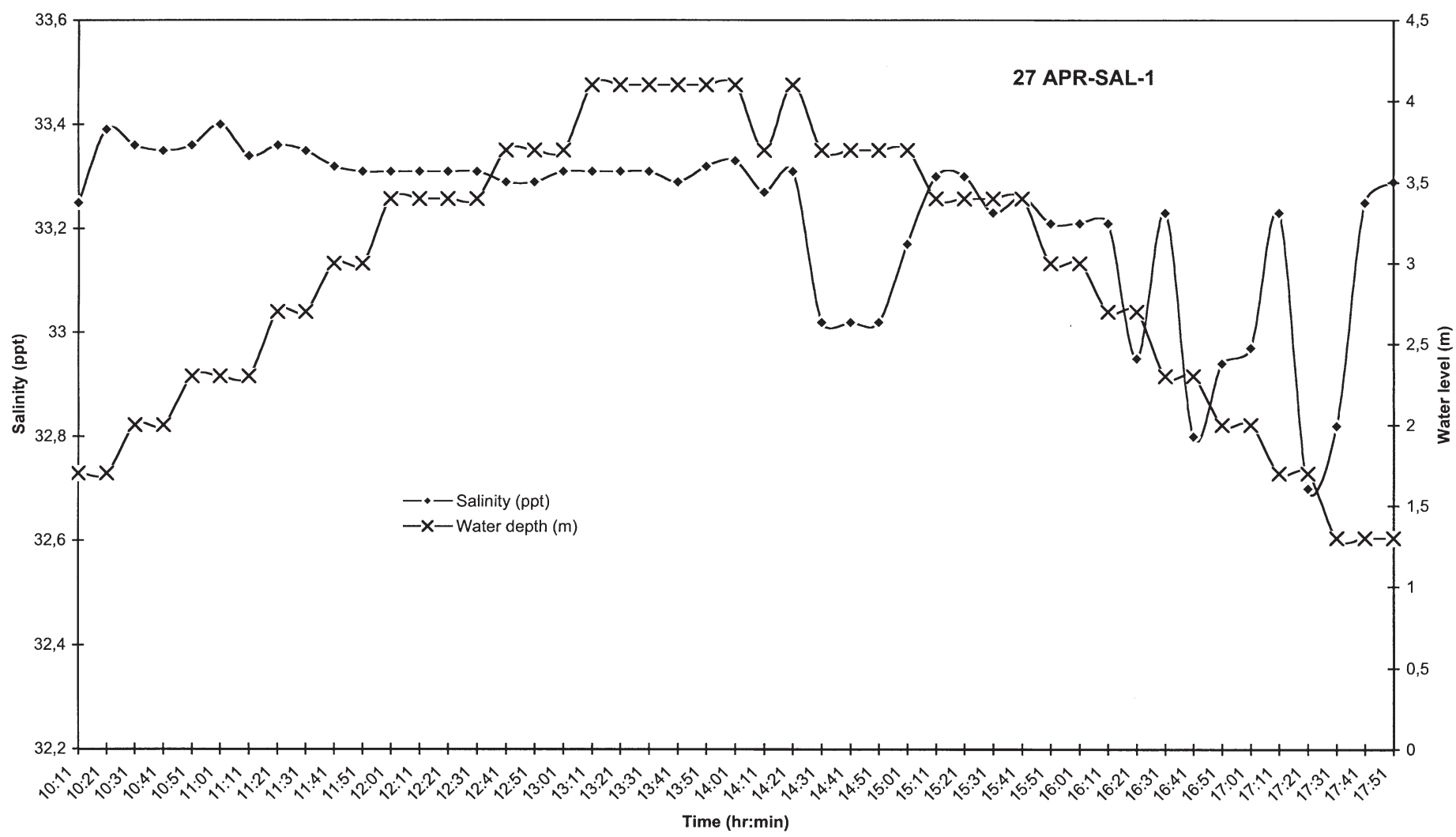

Fig. 2. Coastal salinity levels with changing tide before rainy episode

samples were taken weekly for a period of 1 mo during each season.

\section{RESULTS}

Under normal atmospheric conditions, the coastal waters away from land have salinity values of 34.6 to $34.94 \%$ between April and June (Newell 1957). Close to the beach the salinity values varied between 32 and $35 \%$ during April/May (Fig.2). During this period temperatures lie typically between 29.5 and $30.5^{\circ} \mathrm{C}$. (Fig. 3). These values showed a dramatic change during the heavy rains at the beginning of May 1998. Salinity was substantially lowered to $15 \%$ at low water and remained low, ( 30\%) at high water (Fig. 4). The salinity slowly rose to open water conditions as the rain subsided (Fig. 5). The heavy rain that fell for 2 consecutive days (3/4 May 1998) also resulted in cooling of the coastal waters, to values ranging between 26.5 and $28^{\circ} \mathrm{C}$ in a day (Fig. 6). Sediment accumulation on the tidal flats and beach as a result of the rain episode was substantial (Fig. 7).

\section{DISCUSSION}

Generally, intertidal benthic communities have been observed to be sensitive to extreme salinity and temperature changes such as winter and summer variations. Flemming \& Delafontaine (1994) found that mussles thriving on intertidal banks of the Wadden Sea were substantially depleted during winter. Two factors, namely increased winter wave agitation and extreme temperature change between summer and winter, were identified. In a warm tropical environment where substantial seasonal change in temperature is not expected, changes of the magnitude recorded here may be considered extreme. The observed drop in salinity was also extreme. Excessive sediment supply to the flats in a short period of time buries some of the organisms. The lithic sediments supplied by the small streams to the tidal flats and beach during floods are largely river bank material, which are coarser in grain size than typical tidal flat sediments in the area (Dubi \& Nyandwi 1999). Thus, if such conditions were to persist the benthic communities would have to readjust. 


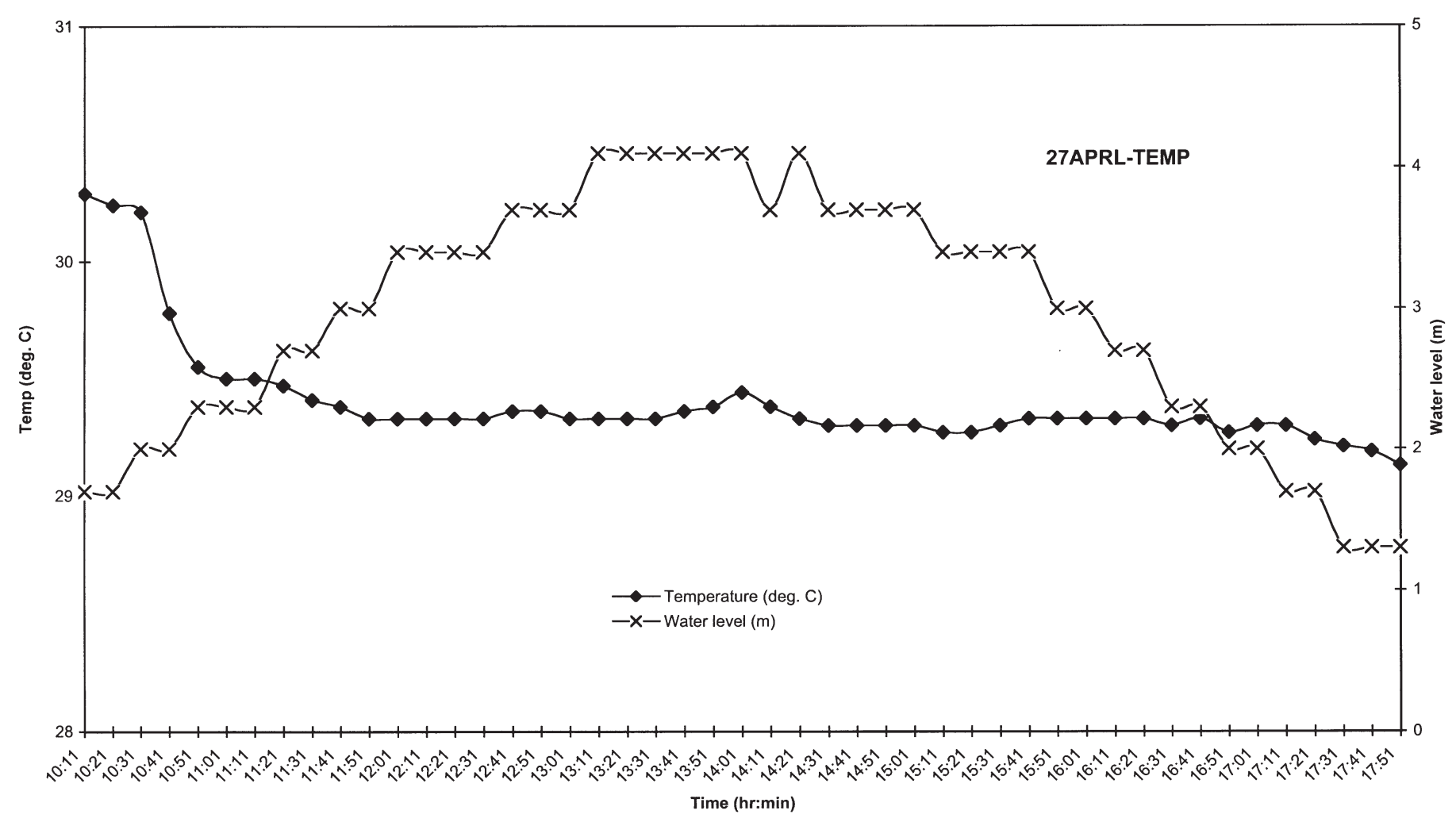

Fig. 3. Coastal water temperature changes with tide stage before rainy episode

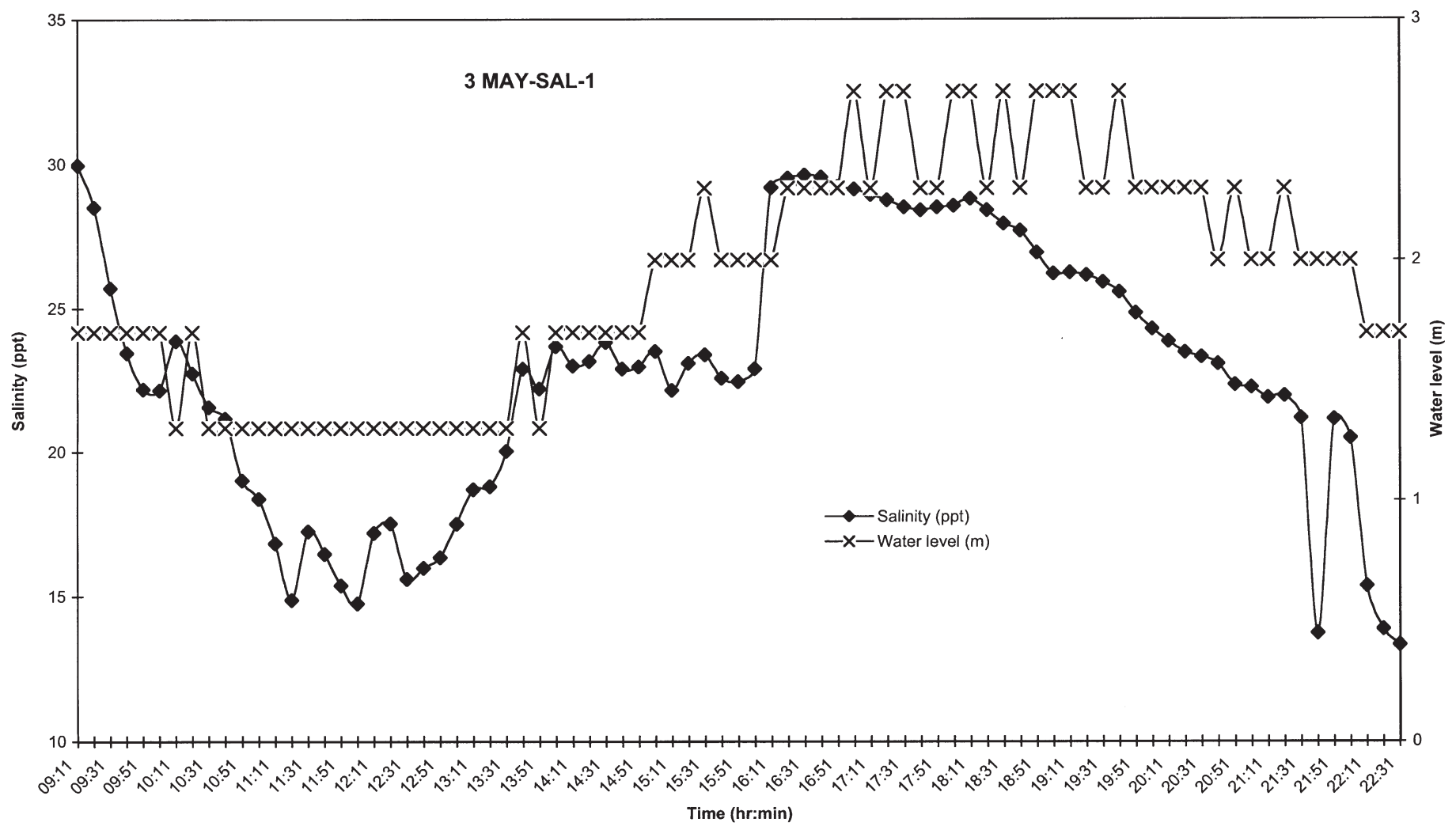

Fig. 4. Abnormally low coastal salinity levels as a result of El Niño rains 


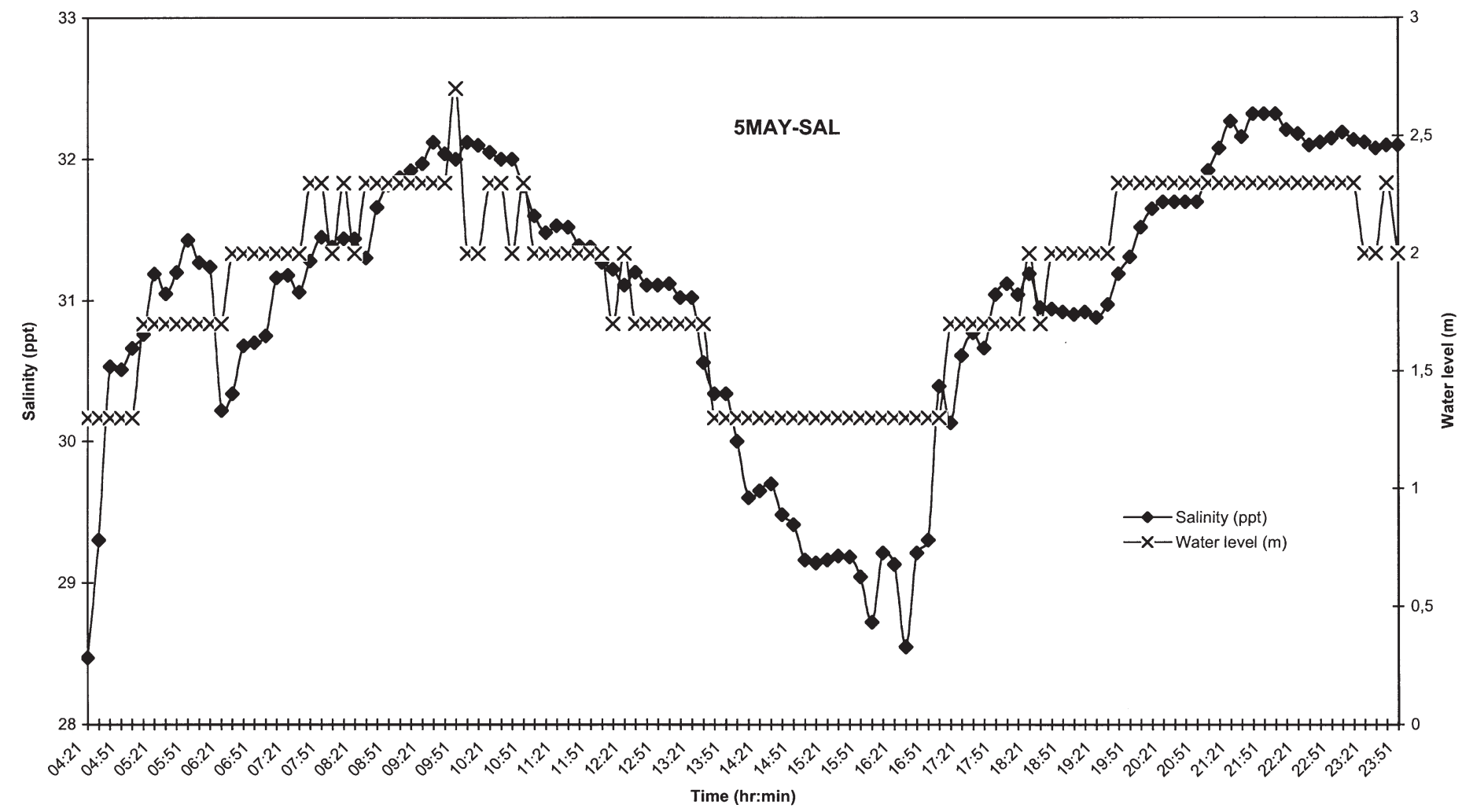

Fig. 5. Coastal salinity levels towards end of rainy episode

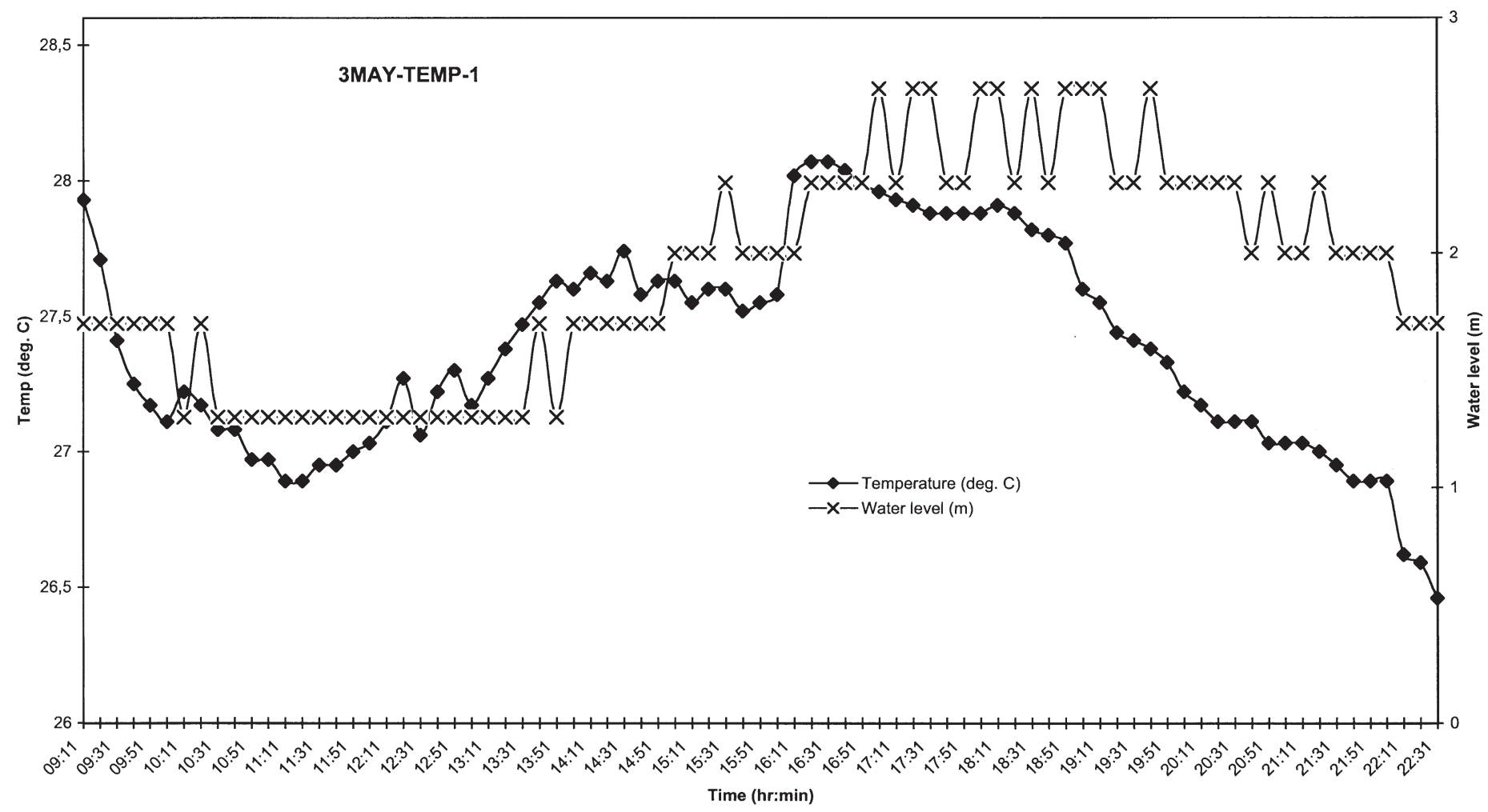

Fig. 6. Coastal water temperature during El Niño rains showing cooling (cf. Fig. 3) 


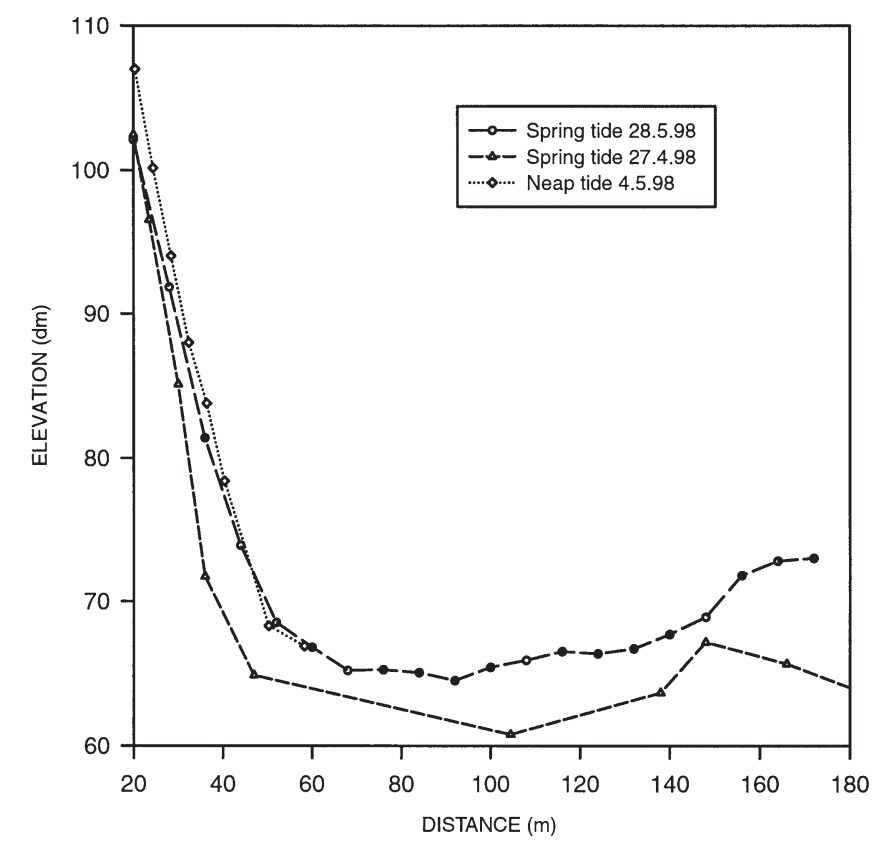

Fig. 7. Beach response to El-Niño rains showing substantial accretion

\section{CONCLUSION}

The El-Niño phenomenon in the Indian Ocean, which in 1998 was accompanied with heavy rains that peaked during the beginning of May, is an episodic event that produces changes in the hydrography of coastal waters. The 1998 event was accompanied by trapping of coastal waters, their dilution, and large sediment supply. The changes are considered significant and could have an effect on the ecological balance of nearshore benthic communities. A distinct positive feature of this episode was the accretion of beaches close to stream entrances. Episodic atmospheric events are therefore an important factor in the stability of the coastal zone.

Acknowledgements. The funding for this project was provided by the Institute of Marine Sciences, University of Dar es Salaam under the Sida-SAREC core support fund for research, and additional funds were provided by the Chief Administrative Officer, University of Dar es Salaam, under a project to study beach erosion and mitigation options for the University's Kuinduchi Marine Biological Station.

\section{LITERATURE CITED}

Dubi AM, Nyandwi N (1999) Preliminary studies for the mitigation and control of coastal erosion at Kunduchi Beach, Dar es Salaam. Institute of Marine Sciences, Zanzibar, Report No. IMS/1999/01

Flemming BW, Delafontaine MT (1994) Biodeposition in a juvenile mussle bed of the east FrisianWadden Sea (southern North Sea). Neth J Aquat Ecol 28(3/4):289-297

Newell BS (1957) A preliminary survey of the hydrography of the British East African coastal waters. Fishery Publications No. 9. HMSO, London

Proofs received from author(s): October 8, 2001 